factors, we suggest that this has two profound implications: firstly, risk factors in the disease will be defined as those that alter expression of the precursor protein gene, and, secondly, effective treatments of Alzheimer's disease will be those targeted at modulating expression of the precursor protein gene.

STEPHEN GENTLEMAN GARETH ROBERTS

Department of Anatomy and Cell Biology,

St Mary's Medical School.

Imperial College Institute of Science Technology and Medicine,

London W2 1 PG

1 Whalley LJ. Risk factors in Alzheimer's disease. BMf 1991;303:1215-6. (16 November.)

2 Van Duijn CM, Hofman A. Risk factors for Alzheimer's disease: a collaborative reanalysis of case-control studies. Int $\mathcal{F}$ Epidemiol 1991;20(suppl 2):1-73.

3 Van Duijn CM, Hendriks L, Cruts M, Hardy JA, Hofman A, Van Broeckhoven C. Amyloid precursor protein gene an Broeckhoven C. Amyloid precursor protein gene
mutation in early-onset Alzheimer's disease. Lancet 1991;337: mutation.

4 Roberts GW, Allsop D, Bruton CJ. The occult aftermath of boxing. F Neurol Neurosurg Psychiatry 1990;53:373-8.

5 Clinton J, Ambler MW, Roberts GW. Post-traumatic Alzheimer's disease: preponderance of a single plaque type. Neuropathol Appl Neurobiol 1991;17:69-74.

6 Roberts GW, Gentleman SM, Lynch A, Graham DI. BA4 amyloid protein deposition in brain after head trauma. Lancet 1991;338: 1422-3.

7 Goate A, Chartier-Harlin M-C, Mullan M, Brown J, Crawford $\mathrm{F}$, Fidani $\mathrm{L}$, et al. Segregation of a missense mutation in the amyloid gene with familial Alzheimer's disease. Noure 1991;349:704-6.

8 Hardy J, Allsop D. Amyloid deposition as the central event in the aetiology of Alzheimer's disease. Trends Pharmacol Sci the aetiology of $\mathrm{A}$
$1991 ; 12: 383-8$.

9 Kawabata S, Higgins GA, Gordon JW. Amyloid plaques, neurofibrillary tangles and neuronal loss in brains of transgenic mice overexpressing a $\mathrm{C}$-terminal fragment of human amyloid precursor protein. Nature (in press)

10 Wisniewski HM, Barcikowska M, Kida E. Phagocytosis of $\beta / A 4$ amyloid fibrils of the neuritic neocortical plaques. Acta Neuropathol 1991;81:588-90.

\section{Chemotherapy in advanced ovarian cancer}

SIR,-The Advanced Ovarian Cancer Trialists Group performed an overview of randomised trials of chemotherapy in advanced ovarian cancer. ${ }^{1}$ I have questions about their conclusion favouring platinum chemotherapy.

They categorised 45 trials into five groups, and many of the trials seem to have had arms that could be included in more than one group. However, there are only four trials in two different groups, and only one trial in three groups. If a trial had an arm that could fit into two groups it should be used twice, and this should be done consistently, to increase the power of the study's findings. The median survivals approximated from the graphs (figs 1, 3, 5, 7, and 9) are 14 months for both arms in group I, 16 and 18 months in group II, 16 and 18 months in group III, 19 and 21 months in group IV, and 22 and 24 months in group V. Some of the difference in the median survival of apparently similar arms may be due to the exclusion of valid subgroups. This increased median survival from group I to group $\mathrm{V}$ may simply be due to stage creep, the Will Rogers phenomenon.

The authors found no significant difference between combinations with and without platinum (comparison III) and also state that there is no evidence that non-platinum drug combinations are superior to non-platinum single agents (comparison I). A reasonable conclusion from these two statements is that there is no clear evidence that platinum based treatment is more effective than a single or non-platinum agent. The reason for stating that "immediate platinum based treatment was better than non-platinum based treatment" is not obvious as the confidence intervals of the relevant curves (figs 1, 3, and 5) show that treatment without a platinum based agent gave equal results.

Logically then, patients could be treated with a regimen such as oral chlorambucil, with com- bination treatment being reserved for subsequent relapse as no difference in survival has been shown. Oral chlorambucil is well tolerated and can be taken as an outpatient and is cheaper than intravenous platinum based regimens. With platinum added into the cost of treatment as second line treatment there would still be advantages in terms of both cost and quality of life. This must be included as an arm in future trials.

Division of Radiation Oncology

Division of Radiation

Westmead,

NSW 2145

Australia

1 Advanced Ovarian Cancer Trialists Group. Chemotherapy in advanced ovarian cancer: an overview of randomised clinical trials. BMF 1991;303:884-93. (12 October.)

2 Feinstein AR, Sosin DM, Wells CK. The Will Rogers phenomenon. Stage migration and new diagnostic techniques as source of misleading statistics for survival in cancer. $N \mathrm{Engl} \mathcal{F}$ Med 1985;312:1604-8.

SIR, - We agree with many of D J Cruickshank's comments ${ }^{1}$ on our overview of randomised clinical trials of chemotherapy in advanced ovarian cancer. He emphasises that in the past clinical practice has been unduly influenced by small, inconclusive trials.

It is true that in the absence of any randomised trials incorporating an untreated control group there is no direct evidence that chemotherapy is beneficial in advanced ovarian cancer. Given the widespread routine use of chemotherapy, however, it would not currently be possible to conduct such a trial. Nevertheless, we are carrying out a trial in early stage disease in which patients are randomised to receive immediate or deferred adjuvant platinum based chemotherapy. This will run concurrently with another trial comparing carboplatin alone with cyclophosphamide, doxorubicin, and cisplatin in advanced disease. $\mathrm{Al}$ though we agree that quality of life studies are extremely important, these can be placed in context only by accurate estimates of survival. Both of these two trials are "large simple trials," and within their flexible framework interested groups can incorporate assessment of quality of life. Indeed, one such study is already planned.

The trial comparing carboplatin with cyclophosphamide, doxorubicin, and cisplatin shows that we are interested in quality as well as quantity of survival. Although we do not agree that the regimen of cyclophosphamide, doxorubicin, and cisplatin is highly toxic, as some of the severe side effects can be controlled with modern antiemetic agents, it is less pleasant treatment than carboplatin alone. As existing information suggests that platinum based combinations ${ }^{2}$ and, in particular, cyclophosphamide, doxorubicin, and cisplatin may improve survival, however, it is necessary to establish whether this is indeed so and the magnitude of any possible effect of treatment. Only then can we consider a reliable cost-benefit analysis of the treatments, including survival, toxicity, and quality of life. Studies of patients' attitudes have shown that they are willing to accept more aggressive treatments in return for very moderate survival benefits. ${ }^{4}$

As there is little reliable information on major prognostic factors in advanced disease the suggested "prognosis oriented treatment strategy" is not feasible at this time. We do, however, believe that further study is required and plan to investigate many prognostic factors when we update the overview next year.

Finally, power calculations were omitted from the article for reasons of space; they are stated clearly in the trial protocols. For the trial comparing carboplatin alone with cyclophosphamide, doxorubicin, and cisplatin in advanced disease, assuming a five year survival of $20 \%, 2000$ patients would enable us to detect a $6 \%$ absolute or $30 \%$ relative improvement at five years $(5 \%$ significance level, $90 \%$ power). For the trial comparing immediate and deferred adjuvant platinum based chemotherapy in early disease, assuming a five year survival of $60 \%, 2000$ patients would enable us to detect an absolute difference of $7 \%$ with the same significance level and power.

L A STEWART D GUTHRIE

M K B PARMAR C J WILLIAMS

Advanced Ovarian Cancer Trialists Group,

MRC Cancer Trials Office,

Cambridge CB2 2BB

Cruickshank DJ. Chemotherapy in advanced ovarian cancer. BMf 1991;303:1269. (16 November.)

2 Advanced Ovarian Cancer Trialists Group. Chemotherapy in advanced ovarian cancer: an overview of randomised clinical trials. BMf 1991;303:884-93. (12 October.)

3 Ovarian Cancer Meta-Analysis Project. CP versus CAP chemotherapy of ovarian carcinoma: a meta-analysis. $\mathcal{I}$ Clin Oncol 1991;9:1668-74.

4 Slevin ML, Stubbs L, Plant HJ, Wilson P, Gregory WM, Armes PJ, et al. Attitudes to chemotherapy: comparing views of patients with cancer with those of doctors, nurses, and general public. $B M F$ 1990;300:1458-60.

\section{Intravenous magnesium in suspected acute myocardial infarction}

SIR, - In their overview of trials of intravenous magnesium salts in acute myocardial infarction Koon $\mathrm{K}$ Teo and colleagues point out ${ }^{1}$ that the largest published study (the first Leicester trial) reported only those deaths occurring during the 24 hours for which magnesium sulphate or saline was infused. ${ }^{2}$ We have now completed a long term follow up of the patients randomised in that study, which took place between October 1983 and May 1984. By using hospital and general practice records and the NHS Central Register we have obtained survival data on $96 \%$ of the patients at one year and $92 \%$ at five years. We have analysed the groups as randomised; the initial report was confined to those in whom myocardial infarction was subsequently confirmed.

The mortality odds ratio and its $95 \%$ confidence interval (magnesium:placebo) were $0.64(0.31$ to $1.33)$ at 28 days after randomisation, $0.77(0.42$ to $1.41)$ at one year, and $0.77(0.47$ to 1.26$)$ at five years. If the 28 day data are used to recalculate the typical odds ratio for all seven studies included in the overview the point estimate is $0.52(0.33$ to $0 \cdot 80$ ), marginally nearer the null value but still suggesting that intravenous magnesium has a substantial protective effect.

Recruitment of about 2400 patients to the second Leicester study is due to be completed in February. The fourth international study of infarct survival, which examines an essentially identical magnesium regimen in a factorial design, has already enrolled over 5000 patients. A clear answer on this intriguing issue is therefore likely to be available before long.

KENT L WOODS

SUSAN FLETCHER LINDSAY F P SMITH

Department of Pharmacology and Therapeutics,

University of Leicester,

Clinical Sciences Building,

Leicester LE2 7LX

1 Teo KK, Yusuf S, Collins R, Held PH, Peto R. Effects of intravenous magnesium in suspected acute myocardial infarction: overview of randomised trials. BMY 1991;303:1499-503. (14 December.)

2 Smith LFP, Heagerty AM, Bing RF, Barnett DB. Intravenous infusion of magnesium sulphate after acute myocardial infarction: effects on arrhythmias and mortality. Int 7 Cardiol 1986;12:175-80.

\section{Urinary incontinence}

SIR, - Though it is laudable to try to provide and evaluate conservative management of incontinence economically in the community, we think that 